\title{
The stress corrosion cracking behaviour of heat-treated Al-Zn-Mg-Cu alloy in modified salt spray fog testing
}

\author{
J. Oñoro
}

\author{
The stress corrosion cracking behaviour of 7075 (Al-Zn-Mg-Cu) alloy have been \\ studied in a salt spray fog chamber with two vapourised aqueous solutions \\ $(0$ and $5 \% \mathrm{NaCl})$. The paper analyses the stress corrosion resistance of 7075 \\ aluminium alloy with several precipitation-ageing heat treatments. The results \\ are compared with that obtained in $3.5 \% \mathrm{NaCl}$ aqueous solution at $20^{\circ} \mathrm{C}$. The \\ salt spray fog testing has permitted a good evaluation of SCC susceptibility in \\ 7075 alloy. All temper conditions studied were susceptible to SCC in the different \\ environments tested. 7075-T6 temper was the most susceptible, while in all the \\ cases studied 7075-T73 temper was the least susceptible. Compared to 7075-T6, \\ 7075-RRA temper improved the resistance against the SCC process, but the \\ mechanical properties obtained were lower.
}

\section{Introduction}

Stress corrosion cracking (SCC) occurs when a susceptible material is subjected to the combined influence of tensile stress, as well as to an aggressive environment. Crack initiation and propagation thus take place in a great variety of metals and alloys. Among the high-strength aluminium alloys, 7075 belongs to the Al-Zn-Mg-Cu group and is widely used in structural elements made of light components, such as in the aeronautical industry. Despite the favourable mechanical behaviour of this alloy, SCC has been detected in different environmental conditions, for example, where the environment is not very aggressive, such as in the case of atmospheric humidity at room temperature $[1,2]$. Cracking is generally initiated on the surface of the component when small surface imperfections generate a fissure that will propagate through the component.

SCC in aluminium alloys is complex and a great number of parameters are involved. Once the crack appears, its growth is influenced by a combination of different factors: the microstructure of the material (heat treatment, level of impurities, manufacturing background, etc.), the stress level, and the aggressive conditions in the environment. The residual stresses associated to welding or fastening have a significant impact on material susceptibility $[2,3]$. The SCC crack growth mechanisms fall into two generic categories: in one, crack propagation occurs via anodic dissolution, and in the other, it is via hydrogen embrittlement. The micro-structural state of the material has been the parameter most studied to find a microstructure

\footnotetext{
1. Oñoro

Ingeniería y Ciencia de los Materiales, Universidad Politécnica de Madrid, ETS Ingenieros Industriales. c/ José Gutierrez Abascal, 2. 28006 Madrid, (Spain)

E-mail: javier.onoro@upm.es
}

resistant to SCC and simultaneously high mechanical properties $[2,4]$, grain-boundary precipitate size and spacing, precipitate free zone width, slip characteristics and grain-boundary segregation has been extensively studied [2]. The precipitation hardening process is directly responsible for SCC susceptibility in highstrength aluminium alloys $[5,6]$. These materials are immune to SCC in the as-quenched condition where grain-boundary precipitation is prevented [7], but they usually become susceptible with increasing precipitation hardening reaching a maximum before peak strength [4]. Over-aged heat treatments decrease SCC susceptibility and hence reduces the strength. A heat treatment known as retrogression and re-ageing (RRA) has been employed with $\mathrm{Al}-\mathrm{Zn}-\mathrm{Mg}-\mathrm{Cu}$ alloys to obtain SCC resistance equivalent to the over-aged temper (T73) together with the maximum strength level (T6) [8-11], beneficial effects of RRA upon SCC susceptibility with respect to $\mathrm{T} 6$ have been attributed to increase in grainboundary precipitate size and spacing. Despite all the work done in this field, SCC continues to be a typical mechanism of failure in these types of alloys.

In the SCC process of aluminium alloys, it is possible to identify two different cracking performances that correspond to the so-called propagation region I and II [12], Fig. 1. Region I is basically dependent on the stress level at the crack tip. Region II, however, does not depend on the level of stress and has been defined as a material corrosion cracking process controlled by a physical-chemical mechanism. This mechanism is identified as an attack of the aggressive elements at the crack tip, which is limited by their diffusion speed from the bulk to the said crack tip. Region I starts at the stress-intensity factor threshold ( $K_{\mathrm{ISCC}}$ ), under whose limit no crack growth exists. Region II ends at the critical stress-intensity factor $\left(K_{\text {Ic }}\right)$ beyond which crack propagation is produced by a mechanical action that does not depend on environmental factors. Crack velocity has been studied by assuming the existence of a principal mechanism that controls 


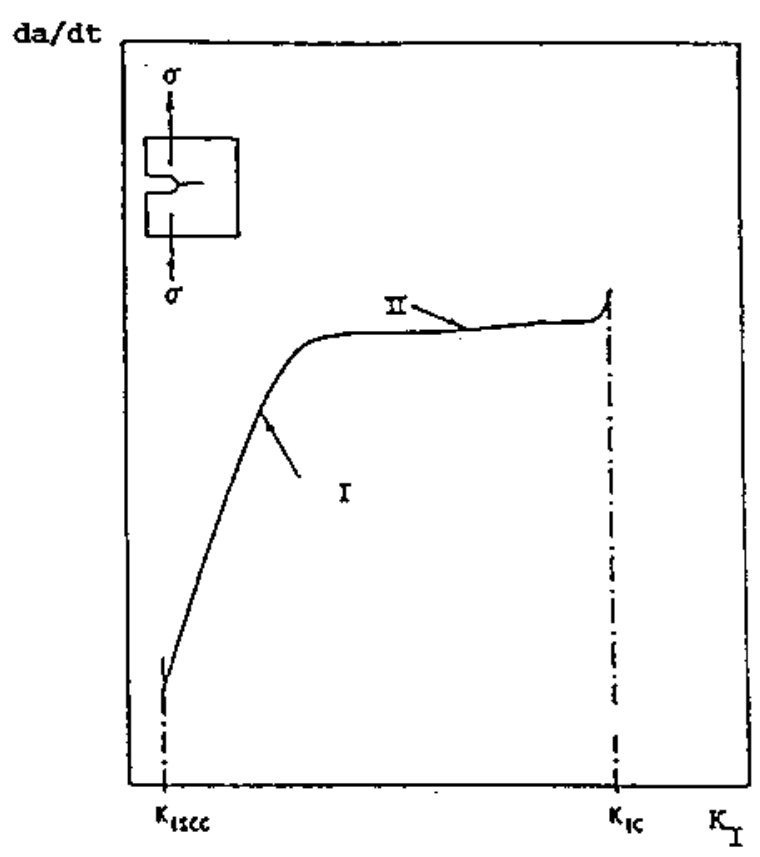

Figure 1. SCC regions I and II

crack growth [4], or by developing macroscopic-empirical parameters that globally describe the phenomenon [13]. On the other hand, the forces generated by corrosion products modify the $K_{\mathrm{ISCC}}$ values, which is improved with over-aged heat treatments [14]. An effective SCC evaluation requires a thorough understanding of the mechanisms that come into play.

The objective of this paper is to analyse the SCC susceptibility of the 7075 (Al-Zn-Mg-Cu) aluminium alloy at different temper conditions exposed in a fog chamber with two aggressive environments.

\section{Experimental}

The SCC tests were carried out with a $25 \mathrm{~mm}$ thick 7075 alloy aluminium plate, Table 1 shows the composition in wt\%. The material was machined into specimens measuring $200 \times 25 \times$ $25 \mathrm{~mm}^{3}$ and subjected to heat treatment. Table 2 shows the different temper heat treatments studied. The heat-treated specimens were mechanically notched and pre-cracked. Crack propagation testing was carried out with bolt-loaded double cantilever beam (DCB) specimens. The stress load was applied with two bolts placed at the crack front that produced a constant displacement (mode I) during the whole testing process. The crack was machined for short-transverse propagation since this direction is the most susceptible to SCC [1].

Table 1. AA-7075 aluminium alloy composition (wt\%)

\begin{tabular}{lcccccccc}
\hline $\mathrm{Al}$ & $\mathrm{Zn}$ & $\mathrm{Mg}$ & $\mathrm{Cu}$ & $\mathrm{Cr}$ & $\mathrm{Si}$ & $\mathrm{Fe}$ & $\mathrm{Mn}$ & $\mathrm{Ti}$ \\
\hline 90.17 & 5.5 & 2.3 & 1.6 & 0.21 & 0.06 & 0.11 & 0.03 & 0.02 \\
\hline
\end{tabular}

Table 2. Precipitation heat treatments applied

\begin{tabular}{lc}
\hline Temper & Precipitation heat treatment \\
\hline 7075 -T6 & $\mathrm{l}$ h at $495^{\circ} \mathrm{C}$, quenched in \\
& water + aged $24 \mathrm{~b}$ at $120^{\circ} \mathrm{C}$ \\
$7075-R R A$ & $\mathrm{~T} 6-10$ min al $200^{\circ} \mathrm{C}$, quenched in \\
& water + re-aged 24 h at $120^{\circ} \mathrm{C}$ \\
$7075-T 73$ & $\mathrm{l}$ h at $495^{\circ} \mathrm{C}$, quenched in \\
& water + aged $1 \mathrm{~h}$ at $107^{\circ} \mathrm{C}$ and 18 h at $168^{\circ} \mathrm{C}$ \\
\hline
\end{tabular}

The SCC study was carried out with the samples exposed to the following aggressive environments:

i. $3.5 \% \mathrm{NaCl}$ aqueous solution at $20^{\circ} \mathrm{C}$.

ii. Fog chamber with $0 \% \mathrm{NaCl}$ at $30^{\circ} \mathrm{C}$.

iii. Fog chamber with $5 \% \mathrm{NaCl}$ at $30^{\circ} \mathrm{C}$.

The samples tested in an aqueous solution were continuously immersed in an aerated thermostatically controlled bath. The test was used as a reference for SCC behaviour of alloy.

The samples tested in the fog chamber were constantly vapourised with an aggressive solution inside a standard cabinet according to ASTM G 85 [15]. The environments described as fog at 0 or $5 \% \mathrm{NaCl}$ were the compositions of aqueous solution spraying in the fog chamber. Three samples were tested in the same heat-treated conditions for each environment for the purposes of reproducibility of the results.

The cracking process was quantified by measuring the fissure on both sides of the sample with a binocular magnifying glass. The cracks were initially measured every $3 \mathrm{~h}$, but when the crack growth was slower, they were then checked every $24 \mathrm{~h}$. The samples remained under test until there was no change in the size of the crack.

Since the geometry of the crack was known, the crack growth rate (v) was obtained as a function of the mode I stress-intensity factor $\left\langle K_{\mathrm{I}}\right\}, v-K_{\mathrm{I}}$ curves, with the following equation:

$K_{\mathrm{I}}=\frac{\delta E h\left[3 h(a+0.6 h)^{2}+h^{3}\right]^{1 / 2}}{4\left[(a+0.6 h)^{3}+h^{2} a\right]}$

where $E$ represents the elastic module, $h$ the half specimen height, $a$ the crack length and $\delta$ the constant displacement at the load point.

DCB samples were used in this study since their geometry makes it possible to obtain different stress-intensity factor values as the crack increases. In the end, either the cracking process is arrested or the sample is completely fractured.

Once the SCC tests were concluded, the cracked specimens were studied. The crack morphology was analysed by scanning electron microscopy (SEM). The influence of the microstructure on crack development was studied by metallographic techniques.

Together with the specimens used for the SCC tests, reference samples were heat-treated in order to characterise the material mechanically. The samples were tested in a universal testing machine. The hardness values were additionally determined for every specimen. 


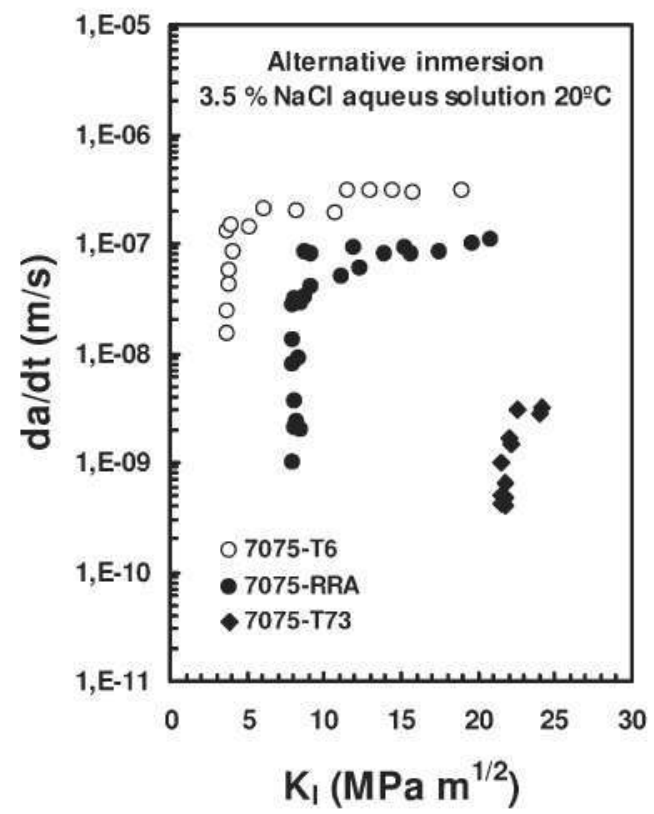

Figure 2. SCC growth rate of $A A-7075$ aluminium alloys in a $3.5 \% \mathrm{NaCl}$ aqueous solution

\section{Results}

The results obtained in the SCC tests are shown in Figs. 2-4. The influence of the stress-intensity factor on crack velocity for the DCB specimens can be observed in these figures. Each figure represents the behaviour of the 7075-type alloy in a specific aggressive environment, subjected to different temper conditions. 7075 aluminium alloy was susceptible to SCC in all the temper conditions studied. The susceptibility of every heat treatment was very different, as is shown in Figs. 3 and 4 . The

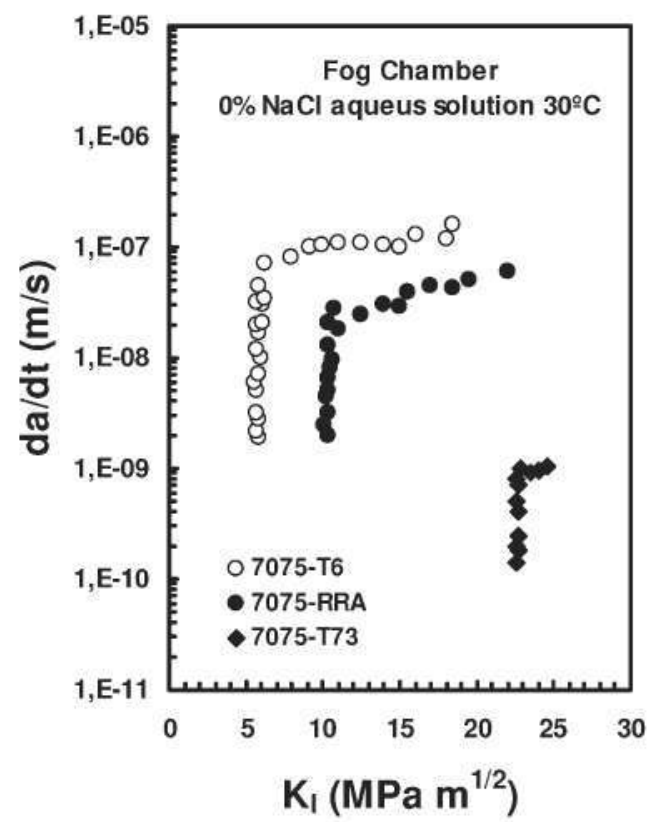

Figure 3. SCC growth rate of $\mathrm{AA}-7075$ aluminium alloys in a $0 \% \mathrm{NaCl}$ fog chamber

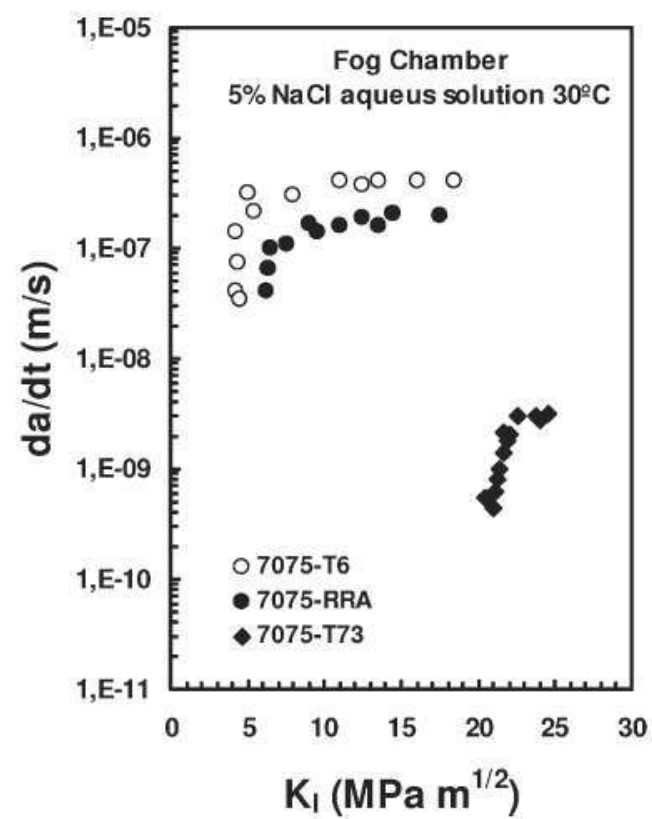

Figure 4. SCC growth rate of AA-7075 aluminium alloys in a $5 \% \mathrm{NaCl}$ fog chamber

crack velocity increased when the concentration of chlorides in the environment was higher, as was expected since the concentration of chlorides specifically causes SCC in this alloy $[1,4]$. The increase was less than an order of magnitude for all the heat treatments, this behaviour is quite similar to the crack velocity observed in 7075-T6 in aqueous environments between distilled water and a saturated sodium chloride solution [2, 4]. In 7075 aluminium alloy, the effect of the sodium chloride concentration over the increase in the SCC in a fog atmosphere has been quite similar to that of an aqueous environment.

The heat treatment precipitation process was analysed by transmission electron microscopy (TEM). The geometry and morphology of precipitation particles around the grain-boundary are shown in Figs. 5-7. T6 heat treatment produces the smallest grain-boundary precipitates ( $21 \mathrm{~nm}$ length and $9 \mathrm{~nm}$ width). RRA heat treatment precipitates are bigger $(28 \mathrm{~nm}$ length and $13 \mathrm{~nm}$

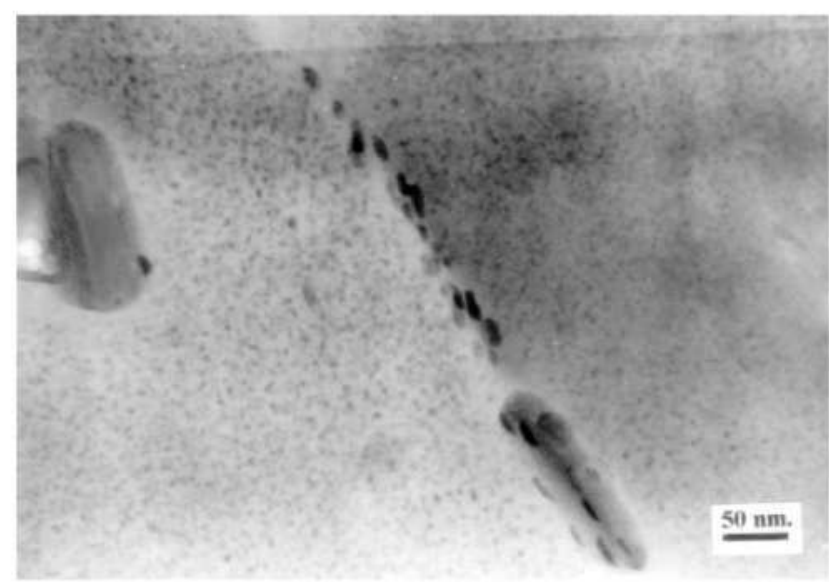

Figure 5. AA-7075-T6. Grain-boundary precipitation morphology 


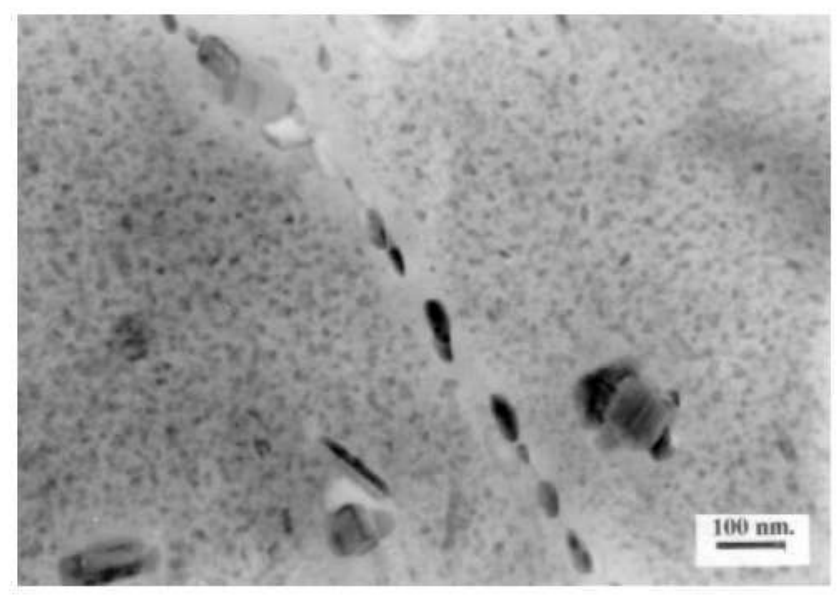

Figure 6. AA-7075-T73. Grain-boundary precipitation morphology

width). T73 heat treatment presents the biggest precipitates ( 54 $\mathrm{nm}$ length and $26 \mathrm{~nm}$ width). The number of grain-boundary precipitates is inverse of the size, i.e. T6 heat treatment presents more and smaller precipitates than RRA, and RRA presents more and smaller precipitates than 173 . The precipitate-free zone width, as reported by others, was found to be independent of ageing [2].

The crack morphology was intergranular in all cases as it is shown in Fig. 8. The propagation was produced in several parallel planes. The crack surface presented an exfoliation morphology.

The results of the tensile and hardness mechanical tests are shown in Table 3. RRA heat treatment maintains the strength and hardness close to T6 properties and is significantly higher than T73.

\section{Discussion}

The method of fog testing is generally applied for specification purposes as accelerated corrosion test to materials exposed to atmosphere. The fail of 7075 alloy component by SCC process has been generally reported in atmospheric environment [2]. The fog

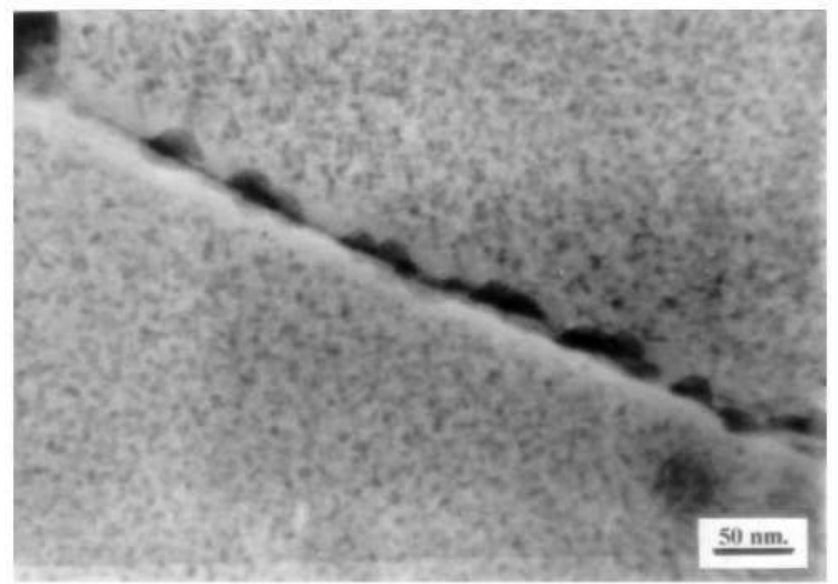

Figure 7. AA-7075-RRA. Grain-boundary precipitation morphology

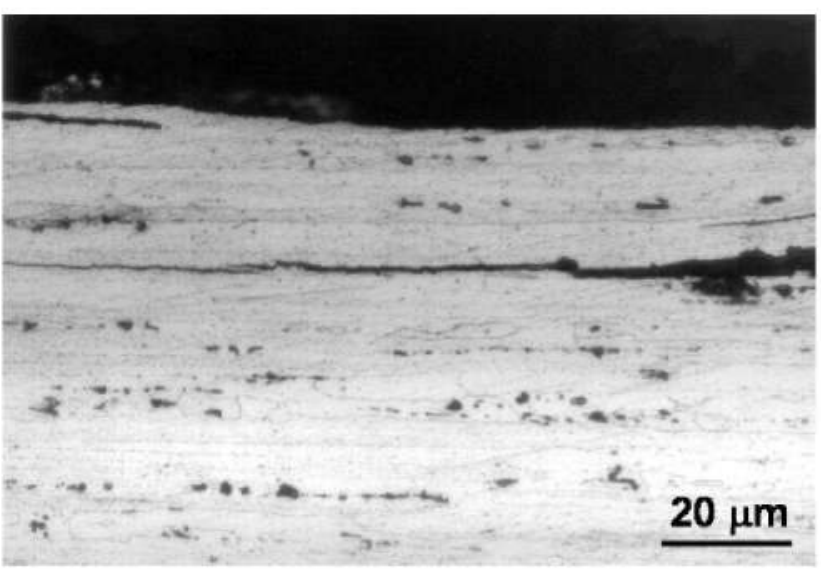

Figure 8. AA-7075-T6. Keller attack. Intergranular cracking

Table 3. Mechanical test results

\begin{tabular}{lccc}
\hline Temper & $\begin{array}{c}\text { Elastic limit } \\
(\mathrm{MPa})\end{array}$ & $\begin{array}{c}\text { Tensile strength } \\
(\mathrm{MPa})\end{array}$ & $\begin{array}{c}\text { Hardness } \\
(\mathrm{HB})\end{array}$ \\
\hline $7075-\mathrm{T} 6$ & 476 & 555 & 180 \\
$7075-\mathrm{RRA}$ & 450 & 550 & 175 \\
$7075-\mathrm{T} 73$ & 408 & 502 & 138 \\
\hline
\end{tabular}

chamber testing has permitted a good evaluation of SCC susceptibility in 7075 alloy.

The T73 artificial-ageing heat treatment was the least susceptible to SCC and the $K_{\text {ISCC }}$ was the highest, the cracks grew only when a significant load was applied (19 $\left.\mathrm{MPa} \mathrm{m}^{1 / 2}\right)$. The coarsest precipitation particles during over-aged T73 heat treatment as shown in Fig. 6 reduces the susceptibility to SCC, but at the same time, reduces the mechanical properties of the alloy as shown in Table 3 .

In all the environments tested, the T6 artificial-ageing heat treatment was the most susceptible to SCC, even in less aggressive conditions such as with vapourised distilled water at $30^{\circ} \mathrm{C}$. The values of crack velocity are high if the load and environmental conditions that exist are taken into account.

If the results of SCC in each heat treatment process is compared to the individual mechanical characteristics, we can see that there is a direct relation between individual mechanical characteristics and a greater susceptibility to SCC when the ultimate tensile stress increases.

The RRA heat treatment was developed to obtain a higher resistance to SCC [10]. Although SCC velocity is significantly reduced compared to the T6 condition, along with a small reduction of the mechanical properties of the T6 temper, it does not attain the more resistant $\mathrm{T} 73$ behaviour and remains within an intermediate zone in all the environmental conditions tested. The RRA treatment carried out has modified the size, geometry and distribution of the precipitation particles around the grainboundary, as shown in Fig. 7, but it was unable to limit the crack velocity to $T 73$ temper behaviour.

The SCC process has an intergranular morphology which is favoured by the granular structure since it was produced in the 
short-transverse direction. This process is verified not only on one plane as it takes place on various parallel planes in the direction of the cracking. The aggressive environmental conditions triggered the formation of corrosive products within the crack with the appearance of mud patterns. The fracture-surface morphology was very similar in all the heat treatments analysed. In general, the samples whose crack velocity was slower, were more intensely attacked at the surface level in the region of the fracture since the said attack was in a smaller area.

\section{Conclusions}

i. The susceptibility to SCC of 7075 aluminium alloy was analysed for different temper heat treatments in a fog chamber with two spraying solutions. All tempers were susceptible to SCC in all the environments studied.

ii. The increase in sodium chloride concentration in the fog chamber produces an increase in SCC velocity that is less in magnitude, although quite similar to the increase reported in aqueous environments.

iii. The 7075-T6 temper alloy was the most susceptible to SCC. The crack velocity, obtained as a function of the stressintensity factor, was higher for this heat treatment in all the aggressive environmental conditions that were analysed. The 7075-T73 temper alloy, however, was the one which exhibited the best SCC behaviour.

iv. Although the RRA heat treatment lowers SCC susceptibility in comparison with the T6 state and slightly lowers the performance of its mechanical properties, it does not succeed in achieving the results obtained with the $T 73$ treatment.

v. It was observed that there is a direct relationship between increased susceptibility to SCC and improved mechanical properties. vi. The crack morphology, which was intergranular in all cases, developed in planes that were parallel to the main cracking direction.

\section{References}

[1] ASM Special Handbook, Aluminum and Aluminum Alloys, J. R. Davis, (Ed.), ASM Handbook, Materials Park, Ohio, USA 1993.

[2] N. J. H. Holroyd, in: Environment-Induced Cracking of Metals, NACE Houston, Texas, USA 1989, pp. 311-345.

[3] J. Schneider, H. Haindl, Mater. Corros. 2008, 59, 753.

[4] M. O. Speidel, Metallur. Trans. 1975, 6A, 631.

[5] T. M. Yue, C. F. Dong, L. J. Yan, H. C. Man, Mater. Lett. 2004, 58,630 .

[6] M. Puiggali, A. Zielinski, J. M. Olive, E. Renauld, D. Desjardins, M. Cid, Corr. Sci. 1998, 40, 805.

[7] G. M. Scamans, N. J. H. Holroyd, C. D. S. Tuck, Corr. Sci. $1985,27,329$.

[8] N. C. Danh, K. Rajan, W. Wallace, Metallur. Trans. 1983, 14A, 1843.

[9] R. N. Lumley, I. J. Polmear, A. J. Morton, Mater. Sci. Technol. 2005, 21, 1025 .

[10] M. U. Islam, W. Wallance, Metals Technol. 1985, 11, 320.

[11] F. Viana, A. M. P. Pinto, H. M. C. Santos, A. B. Lopes, J. Mater. Process Technol. 1999, 92-93, AUG 54.

[12] R. N. Parkins, Corrosion Processes, Applied Science Publishers, London 1982.

[13] J. Oñoro, A. Moreno, C. Ranninger, J. Mater. Sci. 1989, 24, 3888.

[14] D. McNaughtan, M. Worsfold, M. J. Robinson, Corr. Sci. 2003, 45, 2377.

[15] ASTM Standards, G 85-02, Philadelphia, USA, ASTM, 2002.

(Received: January 26, 2009)

W5255

(Accepted: February 13, 2009) 